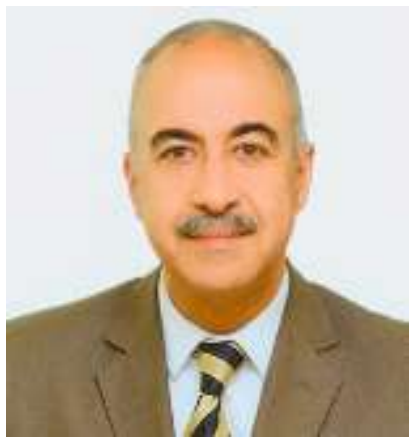

\title{
Does Renewable Energy Still Need Subsidy
}

\author{
Dr. Eng. Mohamed Mostafa El Khayat \\ Chairman of the New and Renewable Energy Authority, NREA \\ Chair of Renewable Energy and Energy efficiency of Arab \\ Experts Committee, League of Arab States, LAS
}

For many decades, it has been stated that renewable energy, RE, needs subsidy, otherwise it will not be able to compete or sustain. For a certain level, this statement was valid. In this period, the investment costs for both wind and photovoltaic, PV, were high. In other words, production costs of both of them reached around 7.0 and 13.0 Cent US\$ per kWh. On the other hand, oil and natural gas, $N G$, prices were low; i.e. less than US\$ 30.0 per oil barrel and around US\$ 4.0 per million British thermal unit, MMBTU, of NG. Also, policies of promoting RE were limited; almost there are two main policies, Feed-in-Tariff, FiT, in limited developed countries and international tenders. As a result, investment in RE was usually led by developed countries and minor share from the developing countries. This was the scene of RE before around 10 years.

Nowadays, the scene of RE totally differs. Starting from the policies side, through auctions in both solar and wind energies, new records of prices have been reached. In numbers, in the field of wind energy Morocco and Egypt already signed contracts with prices lower than 4.0 US\$ Cents $/ \mathrm{kWh}$. For $\mathrm{PV}$, there is a dramatic devaluation in the prices. Now we are speaking for less than 0.7 million US\$ per MW for turnkey projects. As a result, during the last couple of years, the global RE market witnessed a bundle of an outstanding prices, El-Sewihan Project at Abu Dhabi, 2.42 US $\$$ Cent $/ \mathrm{kWh}$. Mexico and Dubai projects, 3.6 and 3.0 US\$ Cent/kWh. Few days ago, Dubai Electricity and Water Authority, DEWA, received $\$ 9.45$ cents per kilowatt-hour for its $200 \mathrm{MW}$ concentrated solar power (CSP) plant.

All these figures, and others, gave us important messages; 1) Despite low prices of oil and NG, RE is able to compete and offer outstanding prices, 2) Wind and PV technologies do not need any kind of subsidy, rather than they need a real free market to compete, 3) CSP is a low hanging fruit and it will witness a frog-leap during the coming couple of years, 4) Even CSP still high, compared with both PV and wind, but is a dispatchable energy. So, it is a game changer. 5) There is a need for more R\&D efforts in storage technology. 6) The role of small-scale applications; i.e. biomass and PV, still need further development in the developing countries. 7) Most of the outstanding recent prices have been fulfilled by developing countries, which means that their role in promoting RE applications, grow year by year.

\section{About Mohammed Mostafa El-Khayat}

Dr. Mohammed Mostafa El-Khayat, got his Ph.D. from Mansoura University Egypt, and the Business Diploma Certificate from Eslsca School of Business, Paris, France. He is the Chairman of the New and Renewable Energy Authority, NREA in Egypt. Also, he is the Chairperson of Renewable Energy and Energy Efficiency Committee, League of Arab State, LAS. He has over 25 years of experience in the fields of Renewable Energy, environment, and academic activities. He is responsible for the wind and solar energy projects. Also, he is responsible for the energy efficiency activities. Dr. El-Khayat shared in drafting Pan Arab Renewable Energy Strategy issued by League of Arab States. Also, he is participating in drafting renewable energy laws and regulations. El-Khayat received many awards from different countries and worked with different regional and international entities. Finally, he issued 5 books and writing a weekly article in Al Ahram Newspaper. 